\title{
Lakeland Terrier
}

National Cancer Institute

\section{Source}

National Cancer Institute. Lakeland Terrier. NCI Thesaurus. Code C53724.

The Lakeland Terrier is a solid, squarely proportioned dog similar to the Welsh Terrier, but a bit smaller. The hard outer coat with its undercoat liner protects the dog from brambles, and bad weather. The long head has bushy hair on the foreface, and the vshaped ears fold over. Puppies are often born dark, but the adult comes in many combinations of black, black and tan, reddish, red grizzle, wheat, liver and blue, grizzle, and grizzle and tan. Height: Not above 141/2 iinches (36.8 cm.) Weight: 15-17 pounds (6.8-7.7 kg.) 